\title{
Multispecies leatherback turtle assemblage from the Oligocene Chandler Bridge and Ashley formations of South Carolina, USA
}

\author{
Bailey R. Fallon and Robert W. Boessenecker \\ Acta Palaeontologica Polonica 65 (4), 2020: $763-776$ doi:https://doi.org/10.4202/app.00740.2020
}

Paleogene dermochelyid species richness far exceeded that of today. Leatherback sea turtles were most species rich in the Paleogene, but their richness declined sharply during the Neogene with only one species existing today, Dermochelys coriacea. We describe the fossil remains of three leatherback genera (Natemys, Psephophorus, and Egyptemys) from the upper Oligocene Chandler Bridge Formation and two (Natemys and Psephophorus) from the lower Oligocene Ashley Formation of South Carolina, USA. The fossils consist of isolated and some associated carapacial ossicles. Several ossicles are referred to Natemys sp. because their scalloped edges are indicative of the carapacial sunflower pattern specific to this genus. Additionally, two Natemys morphotypes (Natemys sp. 1 and 2) are distinguished based on differences in ossicle thickness and internal structure. We refer two ossicles to cf. Psephophorus because of their internal diploic structure and because one has a dorsal radial pattern while the other has a prominent ridge that exhibits strong visceral concavity. Finally, we refer one ossicle to cf. Egyptemys because it has a shallow keel that shows little expression on the visceral surface, although we also acknowledge the ossicle's similarity to some ridged ossicles of the genus Psephophorus. These ossicles represent the first multispecies assemblage of leatherback fossils reported worldwide. Furthermore, the specimens fill both temporal and geographic gaps for extinct leatherback genera and represent the first formally described dermochelyids from South Carolina and the Oligocene of the Atlantic Coastal Plain.

Key words: Chelonioidea, Natemys, Egyptemys, Psephophorus, Paleogene, Oligocene, North America.

Bailey R. Fallon [fallonbr@g.cofc.edu], Department of Geology and Environmental Geosciences, College of Charleston, Charleston, South

Carolina 29424, USA. Robert W. Boessenecker [boesseneckerrw@ cofc.edu], Department of Geology and Environmental Geosciences, College of Charleston, Charleston, South Carolina 29424, USA; University of California Museum of Paleontology, University of California, Berkeley, California 94720, USA. 
This is an open-access article distributed under the terms of the Creative Commons

Attribution License (for details please see creativecommons.org), which permits unrestricted use, distribution, and reproduction in any medium, provided the original author and source are credited.

Forif Full text $(1,102.6 \mathrm{kB})$ 